\title{
In memoriam Alan Peacock: a pioneer in cultural economics
}

\author{
Ilde $\operatorname{Rizzo}^{1} \cdot$ Ruth Towse Th $^{2,3}$
}

Published online: 26 March 2015

(C) Springer Science+Business Media New York 2015

\section{Introduction}

Alan Peacock had a long and very distinguished career in economics, as an adviser to the UK government, as a university administrator and as Chairman of the Scottish Arts Council. He remains a towering figure in cultural economics and was one of the earliest contributors to our subject, in which he worked for over 40 years. He became the first ACEI Distinguished Fellow in 1996, one among the many honours and awards that he received. There have been many obituaries of Alan Peacock and an account of his huge and varied contribution to economics and indeed of his other activities is beyond our scope. Therefore, we concentrate on his contribution to cultural economics and his activities in the arts more generally. The task is certainly made the easier as Alan was a dedicated writer on his interest in these topics, as many readers will know from his Paying the Piper (1993). He continued to do valuable work in cultural economics, particularly in the economics of heritage, until only a year or so before he died.

Before turning to his work in cultural economics, we offer a brief sketch of the beliefs and principles that motivated Alan Peacock's work in economics and, one might almost say, his life. First and foremost he was a classical liberal following in the footsteps of his fellow Scot, Adam Smith. This philosophy has come to be debased as simply a belief in small government and free markets, but Alan was truly liberal in all he thought and did; he was open to new ideas, hated hypocrisy and

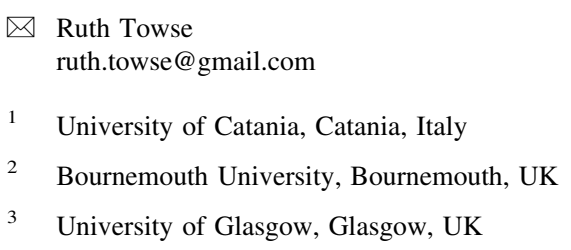


pomposity and in his own way was anti-Establishment, at least that of England. It is therefore not surprising that he was attracted to political economy, welfare economics and public choice theory. This stance put him in league with free market organisations such as the Institute of Economic Affairs and the David Hume Institute in Edinburgh which he founded, and led to his support of the first private university in the UK, University of Buckingham, of which he became the first Vice Chancellor, but he was also Chief Economic Advisor to the UK government's Department of Trade and Industry and chair of the committee of enquiry into the finance of British Broadcasting Corporation (BBC), resulting in the 1986 Peacock Report which was far ahead of its times in recommending the licence fee be replaced by subscription (now being reconsidered but regarded as 'lunatic fringe' at the time); he was knighted for this service. Long before that, he had been awarded the Distinguished Service Cross (DSC) for his wartime service in the Royal Navy. He was also Chairman of the Scottish Arts Council, which entailed membership of the Arts Council of Great Britain (ACGB), of which he was inevitably critical. So Alan had a foot in both worlds as the free-thinking, irreverent Scot and part-time member of the UK establishment. His sardonic sense of humour, great intelligence and integrity carried him though unscathed. In addition to his activities in the UK, Alan Peacock had strong professional connections abroad, especially in Italy, where he was honoured with membership of the Accademia dei Lincei. Eleven European universities acknowledged his academic and professional achievements and conferred him honorary degrees. He was also consultant to many international organisations and to foreign governments throughout the world.

Besides this wide-ranging professional life, Alan Peacock was a keen musician, playing the violin, singing, conducting and composing (he studied composition with Hans Gál, the Viennese composer who had settled in Edinburgh) and this led him to have an interest in the finance of orchestras; one of his first forays into the economics of the arts (which, by the way, was spelt with a capital ' $A$ ' in those more respectful days) was to chair an Arts Council enquiry in 1970 into the London orchestras, of which there were (and still are) four: Peacock recommended they be reduced to two, which stirred up a hornets' nest. Alan loved to refer to economics as the dismal science and did not flinch from applying it as such; he also often said that what governments and similar institutions wanted of economists was a 'hired gun' who would provide the result they wanted to see. He declined to do so and stuck to his belief in independent thinking. He did not 'suffer fools gladly' and could be a hard critic but he was a kind and generous man especially with students and young researchers.

\section{Early work in cultural economics}

Peacock was one of the first critics of what came to be called the 'Cost Disease'. The publication of Baumol and Bowen's article and book $(1965,1966)$ elicited a two-pronged response (Peacock 1969); he questioned whether the diagnosis of the Cost Disease was as serious as they claimed, and secondly, he queried the extent of the external benefits that underlay the welfare economics justification Baumol and Bowen had made for subvention by private or state patronage. Once word about the 
Cost Disease had got around arts councils and ministries of culture, everyone wishing to obtain greater state subsidy used it to make their case and the ACGB was no exception. As a response, Peacock proposed that systematic research be carried out on ACGB's regularly funded performing arts organisations (opera and theatre companies and orchestras) to obtain evidence on the scale of the problem in a period of high inflation such as that experienced in the UK in the 1970s. ACGB supported the research, no doubt believing that it was artistic labour costs that were driving up costs in the performing arts. The research was undertaken by a team based at University of Buckingham and the report duly presented (Peacock et al. 1982). ${ }^{1}$ It found that instead of wage inflation in artists' pay being the cause of price rises, as implied by the Cost Disease, the main source was the cost of materials and the payment of non-artistic workers; the pay of artistic workers had fallen well behind that of other workers. ACGB refused to publicise the report (parts of which are reprinted in Towse 1997) and regarded the expenditure on the research as a waste of money [though not if it had 'proved' their case, as Peacock wryly remarked later (Peacock 1993)].

In the 1970s, empirical research on economics of the performing arts and museums was severely held up by the lack of data on the one hand and the lack of transparency about arts funding on the other (King and Blaug 1976). Peacock, whose specialisation in mainstream economics was public finance, set about tracing the flows of money to an arts organisation from the various sources-central and local government, the BBC, private donations and audiences-which he called 'cultural accounting' (Peacock and Godfrey 1973/1976). This revealed for the first time in the UK what is widely known today (and has changed little) that opera and ballet got the lions' share of the funds and that local government finance was a significant source of finance. This latter finding was important to Peacock who, as a Liberal $^{2}$ at the time, believed in local control and local finance, a theme to which he returned in later work, particularly on heritage. Much has since been achieved in terms of clarity and accuracy in cultural statistics in general, including on finance of the arts and heritage, but at the time these were laborious and thankless exercises that were not welcomed by the arts establishment.

Another basic problem Peacock had grappled with was how to define the output of a performing arts organisation, in particular an orchestra, and to use such social indicators (the contemporary term used for measures of non-commercial activity). It arose in connection with the Arts Council Enquiry into Orchestral Resources and the rather apologetic tone of Peacock's analysis no doubt reflects the hostility that he knew existed towards economists 'meddling' in the world of the arts. The indicators he developed were productivity indices of the four London orchestras using

\footnotetext{
${ }^{1}$ Ruth Towse was one of the team. The task was to go through the books of an arts organisation and itemise costs over a number of years. Artistic labour costs were treated separately from non-artistic labour costs and an index built up. Other costs were calculated under headings that conformed to the National Income Accounts, e.g. rent, insurance, wood (for scenery). Expenditures were then weighted accordingly and compared to inflationary trends in the wider economy. 'Research' involved finding bills in wastepaper baskets and in other incongruous places: accountability to ACGB was not much emphasised in those days!

2 The UK's Liberal Party as it was then called has undergone a number of changes of name.
} 
inflation-adjusted costs and output measured in terms of both performances and seats sold (Peacock 1976/1997). In retrospect, these studies can be seen as forerunners to the 'inflation' study discussed above.

\section{Performing rights}

The experience of these studies on orchestras and the wider performing arts may have recommended him to the commissioners of his next piece of empirical work, this time on composers. In the early 1970s, Peacock was asked by the Performing Rights Society (PRS) for advice on how to set the licence fee it charged the BBC for the music it performed on radio and television. ${ }^{3}$ At the time, the $\mathrm{BBC}$ had a monopsony use of broadcast music and the PRS had (and still has) a monopoly of administering the performing right, one specific right in copyright law. Copyright in musical composition (as with books and other such material) is a set of statutorily created property rights that enables the composer to control the exploitation of his work. Copyrights in musical composition are normally assigned to a music publisher and exploitation takes the form of publication and performance, either 'live' in concerts or in recordings. Recordings may be sold directly to consumers and also played in public performance, for example, on radio and in public places. In order to effectively control these uses of music, both composers and publishers join copyright collecting societies, in this case the PRS, which licenses public performance of music to users through a 'blanket licence' for a fee that is broadly calibrated according to the number of listeners. Revenues from licence fees are distributed to members, and this distribution is a source of income to composers. The monopoly arises because the PRS requires the exclusive assignment of copyrights in order to license use; in addition, it is a natural monopoly due to economies of scale in royalty administration. ${ }^{4}$ The impetus for Peacock's commission came from the referral of the dispute by the BBC to the Performing Right Tribunal; under those circumstances, the Tribunal, the body that regulated copyright disputes in the UK, had the job of resolving the dispute and setting the PRS licence fee. It led Peacock to becoming one of the first writers on the economics of copyright and its administration. Peacock and Weir (1975) attacked the problem de novo in a manner that exhibited Peacock's already developed understanding of the particular problems of the arts and artists; their book Composer in the Marketplace stands up today as one of the best studies of how to analyse copyright administration in economic terms.

The PRS had several concerns that led to Peacock's consultancy: one was the low earnings of many of their composer members and the unequal distribution of distributed income; a second was the increasing use of home taping devices, the main source of unauthorised copying at the time; and the third was the fact that their biggest single customer was the $\mathrm{BBC}$, with its monopoly on music broadcasts of live

\footnotetext{
3 In 1967, Peacock and a group of other economists formed a consultancy partnership, the Economists Advisory Group. The PRS consultancy was Peacock's first consultancy assignment for the group.

${ }^{4}$ For details, see Towse (2013).
} 
concerts and recorded music. Peacock, assisted by Weir, therefore undertook a three-pronged research into composers' earnings (from all sources, not just from royalties), ways of compensating copyright holders for private home taping (for which they recommended the introduction of a 'blank tape' levy) and the de facto bilateral monopoly between PRS and the BBC. They thus conducted a survey of composers' incomes (it was, we believe, the first such research into artists' royalty earnings, a topic in which there has been a lot of recent interest), in addition to their analysis of the economics of copyright administration. Peacock also advised PRS on setting the royalty rate charged to the $\mathrm{BBC}$ for the use of copyrighted music; the previously established formula for determining the rate had been based on the number of BBC licence holders, that is, the equivalent of a specific tax, as Peacock calls it (Peacock 1993, 110-111) - and he now recommended an ad valorem formula based on the BBC's licence revenue. His recommendations were accepted by the PRS and eventually by the Performing Right Tribunal.

These are problems that have only recently attracted the attention of economists and Peacock's analysis of copyright law as a means of overcoming the public good nature of music was novel. ${ }^{5}$ Although it cannot be claimed that Peacock 'invented' the economics of copyright, he recast it into its modern analytical form based on welfare economics and he was very likely the first to write an economic analysis of copyright administration. He accepted the case for government protection for composers' rights via copyright law but rejected the case for nationalising royalty collection services in the UK (the situation in many other countries at the time) on the grounds that governments would not have the incentive to identify all users or to keep down administrative costs. But he recognised that the natural monopoly of royalty collection (of the PRS and other collecting societies dealing with other copyrights) called for regulation, for which he laid out a 'code of good practice' (Peacock 1979; 146). He thus consistently applied his economic analysis of markets and of government to what have now become widely recognised issues in the political economy of copyright law. And, in advising the PRS, he had his first brush with the BBC, with which, as we see, he later had further dealings.

\section{The committee on financing the $\mathrm{BBC}$}

Peacock had spent a couple of years as Chief Economic Adviser to the Board of Trade, which in those days was responsible for broadcasting and hence the BBC licence. The BBC, which is an autonomous corporation, was (and still is) financed by a licence fee levied on the possession of a radio or TV set; the licence fee is set by Parliament and periodically comes up for renewal, presenting the opportunity for political 'discussion' and re-evaluation of its finances. Two issues were at stake in the 1980s: the then Prime Minister, Mrs Thatcher, not only was committed as a sort

\footnotetext{
5 Oddly, The Composer in the Market Place made no reference to the path-breaking contribution to the analysis of copyright by Plant (1934); however, in his 1973 article 'Public Policy and Copyright in Music: An Economic Analysis' [reprinted in Peacock (1979)], Peacock discussed Plant's 1953 exposition of the economics of copyright (Plant 1953). Equally oddly, Ehrlich's well-known 1989 study commissioned by PRS, Harmonious Alliance, barely made reference to Peacock and Weir's seminal work.
} 
of economic religion to privatising any and all public services, she and her Conservative government also believed that the BBC was Left-leaning and she 'had it in' for the BBC. Moreover, the development of cable and satellite transmission now provided alternatives to wireless broadcasting and commercial, advertisingbased broadcasting was competing with the $\mathrm{BBC}$ but not on a level playing field since the $\mathrm{BBC}$ was financed by the licence fee, a matter of constant complaint (then as now) by commercial broadcasters. These circumstances called for a full investigation and Peacock was appointed Chairman of the Committee on Financing the BBC, which reported to Parliament in 1986. It was widely anticipated that Peacock would recommend advertising as a means of financing the BBC but instead, the Committee recommended retention of the licence fee and that it be linked to the Retail Price Index as a neutral basis for maintaining its value. ${ }^{6}$

At the time, little had been written on the economics of broadcasting with the notable exception being two pioneering papers by Coase $(1948,1966)$. Terrestrial broadcasting was traditionally regarded as a public good because transmission is non-rival and non-excludable and, being a natural monopoly with virtually zero marginal costs, marginal cost pricing was not feasible. This economic reasoning justified public intervention (which in many countries meant direct state provision or finance); by the 1980s, with pay-per-view a possibility, Peacock had the opportunity to completely rethink broadcasting finance and apply it to the BBC.

Peacock first set out to establish the aims of broadcasting policy, which '... just as war is too important a matter to be left to the generals and economic policy too important to be left to economists, broadcasting aims are too important to be left to those who do the broadcasting' (Peacock 1986, 3). He made the assumption that the aim of broadcasting is to maximise the satisfaction of viewers and listeners. On efficiency grounds, that seemingly could be met by a competitive market offering a large number of channels and a direct payment mechanism but Peacock believed that the public service element to the BBC meant private finance alone would give rise to free-riding and so to under-provision of external benefits such as educational and cultural programmes; public service broadcasting (psb), in other words, has public good characteristics. Peacock also considered the case for psb on the equity grounds that it should be universally available in remote parts of the country (notably Scotland) and also offer good quality information and entertainment to the less well off, echoing the merit good argument for state finance of the arts and culture. However, he concluded that meeting these objectives did not require that they be supplied by a public corporation with a monopoly and so the recommendation was that the $\mathrm{BBC}$ continue as a psb provider in a more competitive market: public finance of psb should continue, though all creation and delivery of psb content did not have to be done by the BBC.

In several later publications, Peacock reviewed his thoughts about the process and options that he had considered in producing the report. He had contemplated charging for broadcasting but directly subsidising eligible viewers and listeners by means of a voucher in the form of a card that reduced the price for viewing psb

\footnotetext{
6 That was a major issue since inflation was very high in the UK by contemporary standards: it was $18 \%$ in 1980 and had been even higher in the 1970s.
} 
programmes (Peacock 1997a, 306). This was very much in line with his thinking of how to deliver demand side subsidy to the arts through vouchers to less well-off consumers, empowering them rather than subsidising the producer. In a similar vein, he had also considered a governance system for a privatised BBC along the lines of the National Trust, that is, a private non-profit organisation controlled by members. ${ }^{7}$ As with the arts and heritage, broadcasting was another case where Peacock believed the free market would not yield the best result for the consumer; he accepted the case for public support but not for public provision on the grounds that the agent (the Arts Council, the BBC) needed incentives to take more account of the demands of the principal, the viewer.

\section{Heritage}

Alan Peacock's interest in cultural heritage has been pioneering and long lasting. His first work on museums was published early in the seventies (Peacock and Godfrey 1974), and he is credited with writing the first article on the economics of heritage (Peacock 1978). Since then, though involved in many other topics in cultural economics inter alia, as mentioned above, he cultivated a special interest in the economics of heritage and museums throughout his career, culminating in his final publication (Peacock 2013). When he was asked to give the British Academy's Keynes Lecture in 1994, he chose the subject 'The Future of the Past: The Political Economy of Heritage' (Peacock 1994a), which offers the first systematic political economic analysis of the subject, applying to the heritage field an enlarged concept of 'market', to cover all forms of exchange in which negotiations take place and contracts are made. ${ }^{8}$ More recently, the developments of that approach were systematised to draw up 'a possible agenda for heritage policy' including proposals for changes in heritage policy-making (Peacock and Rizzo 2008).

Peacock's contribution to the economics of heritage is deeply influenced by his expertise in public finance and in the economics of government as well as by his liberal roots. Moreover, a distinctive feature of his work is his ability to unite innovative ideas with pragmatic views: his profound knowledge of institutions, supported by his long and varied experience in government and with nongovernmental organisations, is clearly visible when he combines theoretical investigation with a thoroughgoing interest in accounting and measurement issues, ${ }^{9}$ as well as modelling the complex decision-making process and bargaining that underlie cultural policies. He was at ease with 'hot' topics and controversial debates without ever trying to avoid being unpopular with influential professional groups. As an outstanding economist, he was always able to make his case comprehensibly,

\footnotetext{
7 The NPR in the US and psb in the Netherlands is also financed that way.

8 This expansion of the term refers to the negotiations between government departments and the management of heritage organisations and museums over the annual grants, implying also the bargaining over the amount of funding.

9 Public financing of the arts and heritage services in England are analysed in detail in Peacock (2000).
} 
using examples but also anecdotes and a variegated range of multidisciplinary quotations.

In developing his theoretical contribution to cultural heritage, he considered academic borders to be too narrow and always took up the challenge to persuade the relevant actors - 'both those who have a special part to play in nurturing cultural heritage and those who support their efforts, whether expressing their preferences through the market or the public sector'-(Peacock and Rizzo 2008, xiii) that economists' thoughts may offer not only a different point of view but also useful advice (Peacock 2004). He believed both in the importance of culture and the arts and that the related economic problems deserved to be at the forefront of public discussion, and he was concerned about the existence of a 'big gap between economics and the practical world of the stewardship of cultural goods'. He thought that was 'a shame because strong economic analysis can help the arts world hold its own in a competitive age where there are myriad material demands on our time and resources'. Furthermore, 'our citizens deserve that proper consideration be given to how best to deploy taxpayers' funds and legislative powers in this respect'. ${ }^{10} \mathrm{He}$ offers Panmure House ${ }^{11}$ as a case study of the difficulties of this dialogue and the problems of persuading policy makers that economic advice can be useful in coming to a reasoned decision (Peacock 2013). At the same time, he also suggests that to attain that objective, cultural economists need to be careful observers of the real world as a necessary complement to their professional skills in modelling and statistical analysis.

His pioneering 1978 article 'tries to throw some light on the economic problems of 'preserving the past,' using conventional public finance theory' (Peacock 1978, 2). In his view, these problems can be synthesised by saying that the preservation of the past raises the case for public intervention, albeit with varying degrees of publicness related to the features of different types of heritage. However, he made clear that the 'non-reproducible' should not be considered necessarily 'irreplaceable' ${ }^{12}$ and, therefore, that preservation must not be 'at all costs'. Indeed, he was very clear in stating that the preservation of cultural heritage must take resource constraints into account as well as 'whose utility we have in mind' when measuring the costs and benefits of historical preservation. There is no doubt that Alan's interest was always for consumers' utility.

In keeping with his liberal approach, his work in fact was consistently oriented to the enhancement of the role of consumers, that is, those who enjoy heritage services, while also recognising the presence of some form of market failure and the case for public support. His forward-looking definition of cultural heritage is illuminating: heritage is 'an intangible service increasing the utility of consumers, in which historical buildings and artefacts are inputs' (Peacock 1994a, 7). He emphasised the role of the consumer as the 'producer' of his/her own utility, having already in mind

\footnotetext{
${ }^{10}$ Quoted from the foreword to Miers (2006).

11 Panmure House was the residence of Adam Smith for the last 12 years of his life, and it was recently bought by Heriott-Watt University to be used for academic and educational purposes.

12 He recalls the parallel with the arguments put forward by environmental conservationists, who are worried about the 'over-exploitation' of natural resources. Environmental issues had also attracted his attention when he entered the 'heated' debate on climate change in contrast to the 'religious' approach to global warming (Peacock 2008a, b).
} 
the possibilities of substituting heritage inputs generated by technology. Thus, he anticipated the present debate on the relationship between real and virtual consumption generated by new technologies, suggesting that the two are the complementary. ${ }^{13}$ While accepting that the maximisation of consumers' welfare implies that the public authorities help finance, improve information or provide heritage services, Peacock was aware that the involvement of the public sector in the protection, management and evaluation of cultural heritage brings with it the risk that public decisions in cultural heritage are mainly supply-rather than demandoriented. To address that risk, most of his work was devoted over the years to investigating the decision-making process underlying cultural heritage conservation and the production of related services at both levels, i.e. when policies are conceived and when they are implemented, and to devising solutions to enhance consumers' utility. In fact more generally, he was convinced that 'economists could have something to say not only about how to determine what policies regarding public provision are in some sense appropriate, but also about the economic organisation of their provision' (Peacock 2010, 548).

The former issue refers to the determination of the extent of public intervention and of the capability of the political system to express voters' preferences. He raises the interesting question why public support, coupled with regulatory measures to control the provision and sale of historical artefacts, is very well established for heritage while it is much less so in other fields (Peacock 2006). According to him, the answer seems to lie in the fact that governments are sceptical about the ability of individuals to choose the cultural services they enjoy for themselves, with the consequence that producers' interests strongly influence government policy on the grounds that the only guarantee of quality is peer group assessment. Consequently, Peacock identifies the crucial role of experts - the 'cognoscenti', as he labels them-in affecting the stock of heritage as well as the kind of services that can be generated by heritage. As he clearly stresses, certifying what is worth conserving and restoring and how it is influenced by the presence of specialised interests in heritage protection has significant consequences for the allocation and the distribution of resources: the large discretionary power enjoyed by experts hired by government is coupled with the tendency to extend the concept of heritage, while delisting rarely occurs, thus generating a sustainability issue. He cites as evidence for the relevance of public choice theory to heritage policy decisionmaking the observation that experts enjoy an informational advantage and that their decisions are mainly driven by the objective of maximising their reputation with their peers and not necessarily by promoting the 'public interest'.

Alan Peacock strongly rejected a Patrician view of society and, while acknowledging the relevance of experts' advice in deciding what can be done given the 'heritage budget' provided by the public authorities, he denied that experts, using arbitrary value judgments, should decide what ought to be done (Peacock 1997b). ${ }^{14}$ Moreover, experts themselves often disagree profoundly on

\footnotetext{
13 To support this view, he recalls a parallel with the case of taped music and drama.

14 He strongly raised the same issue with respect to international organisations such as UNESCO, for instance, criticising the threat to remove World Heritage status from Edinburgh as a reaction to the planning decisions by Edinburgh Council (Peacock 2008b).
} 
cultural priorities and conservation choices. He contrasts the extreme Ruskinian idea-that there is a moral commitment to preserve everything identified by the 'cognoscenti' as worthy-with some 'sustainable' level of heritage which can stand in comparison with alternative uses of resources, as perceived by society at large. Stressing the concept of 'sustainable heritage', his rather extreme and provocative proposal for a 'workable heritage policy' (Peacock 1997b), aimed at reducing government policy to identifying, maintaining and preserving 'representative historical artefacts'. Without entering into the details of the selection process, it is worth noting that such a proposal implies altering both the size and the composition of the heritage stock and, therefore, among the other things, points towards a more flexible approach for the sale, purchase and loan of heritage items, including on an international scale.

Peacock's contribution clearly demonstrates that different values coexist in the heritage field and how to take them into account is highly controversial. And this is an open and much debated question even among economists, the main issue being whether heritage is relevant 'per se' or because of its instrumental value. ${ }^{15}$ Far from compromising, his basic value judgement was that consumers are the best judges of their own interests without, however, denying that they might be willing to seek information and advice from art experts to improve their understanding and enjoyment and eventually even changing their preferences. Therefore, his efforts were devoted to give voice to the general public or, in other words, to promote consumers' 'empowerment'.

To fulfil that objective, he proposed various possible means. Devolution of political decision-making ${ }^{16}$ was advocated to facilitate more informed debate about cultural issues and to encourage political participation. In his view, where regional governments are able to operate independent cultural policies, including the use of local finance, the role of the national government should be confined to the preservation of the national built heritage and to the definition of minimum standards and rules for the efficient provision of cultural services. Moreover, to 'empower' consumers, he suggests that the public should be represented in those public institutions that advise and manage cultural activities (Peacock 1998). A rapid turnover of the members of advisory bodies and boards is advocated to foster innovation and experimentation. Peacock also assigns great importance to information: on the one hand, the public must be kept fully informed about the rationale of financial provisions and regulations adopted in their interest, and on the other hand, regular surveys of public attitudes to heritage services have to be carried out and the results have to be published.

An associated issue of some importance is how far heritage policies are carried out efficiently. In terms of their implementation and the organisation, Peacock showed that the preservation of historical monuments and, more generally, the supply of heritage-related services can be achieved with a whole variety of methods

\footnotetext{
15 Throsby (2001) distinguishes between economic value and cultural value-the latter reflecting aesthetic, symbolic, spiritual or historical qualities-claiming that it cannot be fully represented in individual monetary valuations.

16 Swiss referenda held on cultural matters are recalled as examples though outlining that such a form of participation cannot be easily 'exported' in countries with centralised systems.
} 
of provision and finance. Public provision does not necessarily mean public production while alternative private/no-profit arrangements can be devised, forming a complex system of transactions among different actors. ${ }^{17}$ When thinking of alternative solutions to public production, he offered several examples of private activities, enhancing market mechanisms for charging and providing evidence of historical services offered with the request of a payment: the commercial management of British 'stately home' properties, the 'clubs' aimed at fulfilling demand for specific preservation ${ }^{18}$ and the non-profit making institutions with more general aims, responsible for segments of heritage provision, the most prominent example being the National Trust. ${ }^{19}$

In most cases, however, public bodies are directly involved-either just as funders or also as providers - in museums and galleries as well as in historical sites. For any form of government financial support to cultural activities, whether to private or to state-owned and operated organisations, Peacock strongly advocated the use of appraisal techniques and some form of monitoring of the recipient's performance (Peacock 2003). His general point was the need for some kind of simulated pricing system to offer an incentive to the recipient to act efficiently, suggesting the use of performance indicators to track the relationship between plans and outcomes. However, he wisely suggests caution in the use of indicators to influence organisations' performance. In fact, he was well aware of the problems involved when applying microeconomics to museums and galleries and in general to heritage institutions, by treating them as firms and trying to measure their output. Dealing with what are multi-product organisations implies taking into account their many different dimensions and a single measure would be misleading. Recognising that a long list of possible physical as well as monetary indicators of output can be devised and also taking quality into account, Peacock's warning was that the elaboration of output indicators can be pursued almost endlessly, the only constraints being the availability of data and the costs of such an activity (Peacock and Rizzo 2008). Based on his own considerable experience, he clearly suggests avoiding a 'deterministic' approach in figuring out the relationship between the funding authority and the heritage organisation; in realistic terms, he thought that the difficult task of overcoming their unwillingness to be 'transparent' should be addressed with some form of contractual arrangement between the funding authorities and subsidised organisations about the choice of indicators as well as what is expected of them. ${ }^{20}$

\footnotetext{
17 The complexity of decision-making and of the underlying bargaining are well stylised in a 'Transaction matrix' (Peacock 1994b) representing the main groups of decision-makers providing and receiving finance as well as the relative importance of different (public/private) sectors in financing cultural heritage and museum and galleries and of the relative importance, in financial terms, of each cultural sector.

18 An example is offered by the Railway Preservation Societies, which have bought stretches of redundant railway lines from the nationalised railway system to conserve the interest in old steam trains.

19 National Trust began as an owner of extensive property and land 'held in trust' and has become the largest single private landowner in Britain. Its membership has grown from 7100 in 1939 up to about 2,500,000 nowadays (Peacock and Rizzo 2008).

20 Historic Scotland-an Agency responsible to the Scottish Executive for Scotland's built heritage-is offered as a positive example of transparency for its reports where achievements are set out against targets (Peacock et al. 2001).
} 
Peacock's pioneering investigation of the funding system for museums and heritage organisations led to his main concern that, with public funding, the managers of heritage organisations hardly have an incentive to use their discretion to promote 'the public interest'. While being aware that there cannot be a unique recipe to design the 'optimal' model of finance of heritage preservation for all countries, since institutional differences matter as well as the differences in tastes and preferences, he always advocated forms of funding that would stimulate decision-makers to be accountable. Already in the 1970s, Peacock was very much in favour of museums charging entrance fees which, as Towse (2005) recalls, were very strongly opposed by Robbins, then Chairman of the Board of the National Gallery. ${ }^{21}$ However, he extended his case for charging more generally to all heritage organisations as a means of providing the management with signals about consumer preferences, enhancing competition and thus generating incentives to improve their services. At the same time, he also strongly advocated the use of matching grants to incentivise efforts to raise funds from private sources, including ticket sales and similar charges paid by the public. ${ }^{22}$

\section{Final remarks}

There can be no final assessment of the importance of any individual's work and publications as only time will tell. To date, Alan Peacock's early work on cultural economics appears to have as much relevance today as when it was produced, so we may expect the same to be true of his later work. For us, the reason is his unique combination of theory and practice and his readiness to investigate new and controversial issues: his cultural economics was intimately related to his expertise in economics in general and that was tempered by his commitment to empirical investigation and he applied all these qualities to issues that he cared about deeply in his personal life-music, the arts, heritage among others-while never letting them intrude into his professionalism. But it was not only in the academic sphere that he exercised these interests: he also did so in his public roles as advisor and arts administrator and they in turn fed into his academic understanding. His 50 year commitment to cultural economics has moulded the subject and opened a series of new doors for exploration. That is his legacy to us.

Acknowledgments Thanks to Anna Mignosa and David Throsby for reading the manuscript.

\footnotetext{
$\overline{21}$ With respect to the Peacock and Godfrey article, Alan wryly recalls that "A prominent gallery director attacked this article, claiming that it was the blueprint for the introduction of charging in British MGs by the Thatcher Government! AP makes no claim to have such direct influence on Government arts policies!" (Peacock and Rizzo 2008, p. 106).

${ }^{22}$ In general, the principles underlying the design of subsidies for the arts are investigated in Peacock (1994b).
} 


\section{References}

Baumol, W., \& Bowen, W. (1965). On the performing arts: An anatomy of their economic problems. American Economic Review, 55, 495-502.

Baumol, W., \& Bowen, W. (1966). Performing arts: The economic dilemma. New York: Twentieth Century Fund.

Coase, R. (1948). Wire Broadcasting in Britain. Economica, 15, 194-220.

Coase, R. (1966). The Economics of Broadcasting and Government Policy. American Economic Review, $56,440-447$.

Ehrlich, C. (1989). Harmonious alliance: A history of the performing right society. Oxford: Oxford University Press.

King, K., \& Blaug, M. (1976). Does the arts council know what it is doing? In M. Blaug (Ed.), The economics of the arts (pp. 101-125). Oxford: Martin Robertson.

Miers, T. (2006). Old stones in a new setting. Breathing new life into Scotland's built heritage (Vol. 10). Edinburgh: Policy Institute.

Peacock, A. (1969). Welfare economics and public subsidies to the arts. Manchester School of Economic and Social Studies, 4, 323-35 [reprinted in Towse (1997), vol. 2, 501-513].

Peacock, A. (1976). The "output" of the London orchestras 1966-75. The Musical Times, 117 (1602), 641-644 [reprinted in Towse (1997), vol. 1, 298-301].

Peacock, A. (1978). Preserving the past: An international economic dilemma. Journal of Cultural Economics, 2, 1-11.

Peacock, A. (1979). The economic analysis of government. Oxford: Martin Robertson.

Peacock, A. (1986). Making sense of broadcasting finance. Stirling, Robbins lecture. University of Stirling [reprinted in Towse, R. (1997), vol. 1, 435-448].

Peacock, A. (1993). Paying the piper: Culture, music, money. Edinburgh: Edinburgh University Press.

Peacock, A. (1994a). A future for the past. Keynes lecture, London. Proceedings of the British Academy (Vol. 87, pp. 198-226), and Hume occasional paper no. 44 [reprinted in Towse (1997) vol. 1, 387-424].

Peacock, A. (1994b). The design and operation of public funding of the arts: An economist view. In A. Peacock \& I. Rizzo (Eds.), Cultural economics and cultural policies (pp. 167-184). Dordrecht: Kluwer.

Peacock, A. (1997a). Political economy of economic freedom. Cheltenham: Edward Elgar.

Peacock, A. (1997b). Toward a workable heritage policy. In M. Hutter \& I. Rizzo (Eds.), Economic perspectives on cultural heritage (pp. 225-235). Dordrecht: Kluwer.

Peacock, A. (1998). The economist and heritage policy: A review of the issues. In A. Peacock (Ed.), Does the past have a future? (Vol. 47, pp. 1-26). London: IEA.

Peacock, A. (2000). Public financing of the arts in England. Fiscal Studies, 21(2), 171-205.

Peacock, A. (2003). Performance indicators and cultural policy. Economia della cultura, 13, 1-10.

Peacock, A. (2004). The credibility of cultural economists', advice to governments. In V. A. Ginsburgh (ed.), Economics of art and culture (pp. 165-178). Amsterdam: Elsevier (paper presented at the ACEI conference, Rotterdam, June. http://www.fhk.eur.nl/evenementen/acei2002/index.html).

Peacock, A. (2006). The arts and economic policy. In V. A. Ginsburgh \& D. Throsby (Eds.), Handbook of the economics of art and culture (Vol. 1, pp. 1124-1140). Amsterdam: Elsevier

Peacock, A. (2008a). Climate change, religion and human freedom. In C. Robinson (Ed.), Climate change policy: Challenging the activists (pp. 114-131). London: IEA.

Peacock, A. (2008). UNESCO's role is rather like that of the good food guide. The Scotsman, 28 August.

Peacock, A. (2010). Public economics and history of economic thought: A personal memoir. The European Journal of the History of Economic Thought, 17(4), 543-557.

Peacock, A. (2013). Adam Smith has returned to live in Edinburgh: A case study. In I. Rizzo \& A. Mignosa (Eds.), Handbook on the economics of cultural heritage (pp. 491-498). Cheltenham: Edward Elgar.

Peacock, A., \& Godfrey, C. (1973). Cultural accounting. Social Trends, 61-65 [reprinted in M. Blaug (ed.), The Economics of the Arts, Oxford: Martin Robertson, 87-100].

Peacock, A., \& Godfrey, C. (1974). The economics of museums and galleries. Lloyds Bank Review, 111, 17-28 [reprinted in Towse, R. (1997), vol. 1, 364-375].

Peacock, A., Jamieson, B., \& Murray-Watson, A. (2001). Behind the curtain: Arts funding in Scotland. In Calling the tune. A critique of arts funding in Scotland (Vol. 2). Edinburgh: Hume Policy Institute. 
Peacock, A., \& Rizzo, I. (2008). The heritage game. Economics, policy and practices. Oxford: Oxford University Press.

Peacock, A., Shoesmith, E., \& Millner, G. (1982). Inflation and the performed arts. London: Arts Council of Great Britain [excerpts reprinted in Towse (1997), vol. 2, 319-60].

Peacock, A., \& Weir, R. (1975). The composer in the market place. London: Faber Music.

Plant, A. (1934). The economic aspects of copyright in books. Economica, 1, 167-195.

Plant, A. (1953). The new commerce in intellectual ideas and property. Stamp Memorial Lecture. London: Athlone Press.

Throsby, D. (2001). Economics and culture. Cambridge: Cambridge University Press.

Towse, R. (Ed.). (1997). Cultural economics: The arts, the heritage and the media industries (Vols. I, II). Aldershot: Edward Elgar.

Towse, R. (2005). Alan Peacock and cultural economics. The Economic Journal, 115, 262-276.

Towse, R. (2013). The economic effects of digitization on the administration of musical copyrights. Review of Economic Research on Copyright Issues, 10(2), 55-67. 